\title{
AN EMPIRICAL ANALYSIS OF THE INFLUENCE OF RISK FACTORS ON THE FREQUENCY AND IMPACT OF SEVERE EVENTS ON THE SUPPLY CHAIN IN THE CZECH REPUBLIC
}

DOI: 10.12776/QIP.V18I2.416

\author{
JOSÉ MARÍA CARIDAD Y OCERIN, JANA HANČLOVÁ, \\ JOSEF ČERNÝ
}

Received 7 November 2014, Revised 20 November 2014, Accepted 28 November 2014

\section{INTRODUCTION}

Dynamic changes in the world bring not only threats but also opportunities. Companies are exposed to many risks because of the need for adequate and appropriate reactions to the changing environment. Businesses need to be flexible and/or agile in order to remain competitive. Recently, the focus in a management science has been changed from the behaviour of individual companies to the management of whole chains or networks of companies, usually called the supply chains or supply networks. The performance of an individual company in the chain depends on the performances and activities of other companies in the chain. This becomes the starting point for the coordination of efforts of practitioners and academicians in order to model supply chains.

The main challenge of risk management is the methodical identification and reduction of risks for a successful realisation of the business objectives. Thereby chances and risks need to be systematically identified and rated regarding their incidence rate and then potential influence on the given business objectives. The intention is to prevent or reduce negative impacts and to increase chances.

In this article, there is analysed and evaluated how risk factors influence various severe events in supply chains' flows of materials, finance and information. The focus primarily falls on manufacturing and distribution enterprises. The research activities are based on the specific conditions of the Czech Republic during the turbulent time period of the year 2010, when the world economy's crisis took its disturbing effects.

The structure of this paper is as follows. First, the role and challenges of Supply Chain Risk Management (SCRM) in a turbulent environment are presented. 
Further, the main goal of this paper and its structure is introduced. Section 2 includes a review of supporting literature for defining Supply Chain Risk Management. Section 3 addresses itself to methods of the survey and the procedures used in the analysis of the survey results. Section 4 contains the questionnaire structure, the procedures for data collection, and the identification of respondents. Section 5 up section 7 contain the empirical part. Section 5 evaluates severe events according to their frequency of occurrence and the level of their impact on a company. In the following section, partial and grouped risk factors in SC of focusing companies are identified, analysed and evaluated. Section 7 quantifies the dependency of critical events on risk factors and the sequential classification allows the clusters to be chosen according to the importance of the relationships. Finally, the conclusions section discusses and summarizes the results.

\section{LITERATURE REVIEW AND HYPOTHESIS}

Supply chain risk management (SCRM) is aimed at developing an approach to the identification, assessment, analysis and treatment of areas of vulnerability and risk in supply chains. There are number of processes which manifest themselves in increasing the risks, such as the increased use of outsourcing, globalisation, reduction of the supplier base, increased demand for on-time deliveries or shorter product life cycles (Norrman and Jansson, 2004).

\subsection{Issues in supply chain risk management}

The Supply Chain Management (SCM) means a proactive relationship and integration among various tiers in the chain (Trkman, et al., 2007). We will follow the definition of SCM by the Council of Supply Management Professionals: "Supply chain management is an integrating function with primary responsibility for linking major business functions and business processes within and across companies into a cohesive and high-performing business model. It includes all of the logistics management activities noted above, as well as manufacturing operations, and it drives coordination of processes and activities with and across marketing, sales, product design, finance, and information technology" (Council, 2013, p. 187).

In the literature review, a supply chain is shown as a system from multi-stage companies with interrelationships among them. Different events influence the system from the outside and also they occur inside the system (Dorcak and Delina, 2011). There are also events among them which can have a risky character and strong impact on the performance of not only one focus company but the performance of all companies integrated in supply chain or network. It means that supply chains need to handle risks to reduce the impact of shocks such as costs increasing, revenues decreasing, smaller or negative synergies given by supply chain integration. For companies which are part of complex supply chains structures, risk management is getting increasingly important. This 
development is the result of actual trends that can be observed, especially in manufacturing enterprises (Basl and Doucek, 2013).

Supply Chain Risk Management can be defined by Tang (2006) as the management of supply chain risks through co-ordination or collaboration among the supply chain partners so as to ensure profitability and continuity. SCM also means a proactive relationship and integration among the various tiers in the chain and, in practice, it means increased dependency between companies and also increased exposure to risks facing other companies.

The process of risk management can be divided into following parts - supply chain (SC) risk identification, risk analysis, and design of appropriate response to risks. In these phases, the various tools for solution can be used (Waters, 2007). For the supply chain risk identification mapping, SC audit, five whys, cause-andeffect diagrams, Pareto analyses, and checklists can be used. For the risk analysis various methods can be used, such as FMEA, scenario analysis, simulation, and network modelling. In the last phase, reduction of risks and their implications, transfer, share or deflect of risks, and creating of contingency plans can be utilized. Macurová, et al. (2011) focus their attention on treatment with risks in logistics on the basis of questionnaire survey outcomes in selected companies in the Czech Republic. Findings provide evidence that it is necessary to the systematic risk management in SC.

Matook, et al. (2009) develop a five stage framework for supplier risk management - entailing supplier risk identification, assessment of supplier risks, reporting and decision of supplier risks, supplier risk management responses, and supplier risk performance outcomes. The operation of the framework is illustrated in a single case study of a UK firm. Factor analysis is used as an analytical tool. Blome and Schoenherr (2011) and Delina and Drab (2010) use a multiple case study approach to investigate successful approaches and experiences by companies in dealing with supply chain risks. Authors develop a set of propositions about how companies manage supply risks in financial crises and illustrate how risk management approaches have shifted and how they are related to Enterprise Risk Management.

\subsection{Risk definition and classification}

The term risk has different meanings in a lot of disciplines. In everyday life the term risk is reduced to the possibility or the increased feasibility of the admittance of a negative rated incident. Business risk by Veber (2000) presents a danger of business failure, which is connected with the hope of achieving remarkably good economic performance. Business risk has two sides, positive (chances), which is connected with hope of success, with applying on the market and achieving a high profit; and negative (dangers), showed by the danger of achieving poorer economic performance than expected, or the occurrence of loss or even bankruptcy. According to Tang and Musa (2011), risk sometimes is interpreted as unreliable and uncertain resources creating supply chain interruption, whereas uncertainty can be explained as matching risk between 
supply and demand in supply chain processes. They carry out a literature review survey in order to identify and classify potential risk associated with different material, cash and informational flows. They mention a significant research gaps, especially in the lack of quantitative models and of information flows risks attention.

There are several different classifications of risks and they focus only on the prediction of disruptive events too often instead of the root causes of uncertainties. Trkman and McCormack (2009) emphasize that the important and often neglected risk factors are market, technology, and environmental turbulence in a supplier's particular market segment, influencing the relationship between supplier's attributes, performance in a SC, and the potential for disruptions. The theoretical background of their model is contingency theory. Risks may be divided into operational and disruption risks (Tang, 2006). A complementary division distinguishes between strategic, tactical and operational risks (Ritchie and Brindley, 2007).

Hunter, et al. (2004) classified risks based on their probability and importance. Even subsets of risk were further classified into risks from the environment of customers/demand, suppliers and technology (Li and Lin, 2006). Earlier research often neglects an important division of risks according to the origin/sources into endogenous and exogenous risks. In this case, it is important to monitor if we deal with the risk sources at a single company level or at a more extensive SC network level. In the second point of view, the risk classification can be extended into risks arising from co-ordinating supply and demand (external risks), and risks arising from internal disruptions.

In this paper, our focus will start from the risk classification shown in Figure 1, where risk factors are structured into space-framed risks (internal risks inside a company, risks of the relationship between organisations, and external environment risks) and logistic flows-framed risks (risks of physical, financial, and information flows).

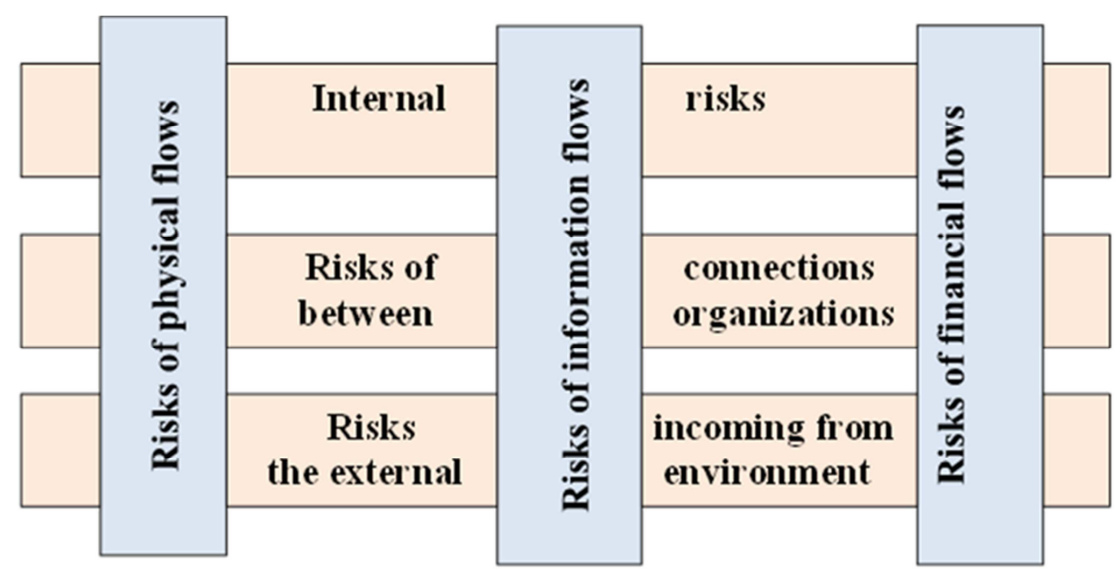

Figure 1 - Viewpoints at risks classification applied in this paper 


\subsection{Formulation of specific objectives}

This paper will follow the analysis and valuation of frequencies and impact of severe events in selected companies of SC in context with assessing the relations to risk factors. The proposed methodology uses the results of a questionnaire survey in manufacturing and distribution enterprises in the Czech Republic in 2010. From the literature review above, the main problems of SCRM can be summarized as follows:

- $\mathrm{SC}$ is an inherently risky function and it has a strong influence on company performance. Because of the mutual cross connections of processes in SCM, the holistic approach to SC is necessary for risk management, coordination and cooperation among subdivisions inside a company but also among companies involved in SC.

- SCRM has recently been developed at both the internal and external level, but the turbulent environment and globalization process increase the risks frequency and their impact in and on SC.

- Risks of the linkages among members of SC are also highly significant. Agreed and standardized procedures for risk management do not exist.

In this context, following partial objectives will be formulated and empirically verified:

- Determination of the critical severe events in SC in terms of their frequency and the intensity of their impact on the company's performance.

- Classification of the risk factors as the source for severe events, according to their significance and variability.

- Quantification of the relations of the influence of a risk factor in a severe event and classification of the relations into clusters according to the frequency and significance of the impact.

\section{METHODOLOGY}

In this section, we consider the methods and tools for:

- analysis and evaluation of severe events and risk factors,

- examining an asymmetric measure of the dependency intensity of frequency, respectively impact, of a severe event on selected risk sources.

For a classification of statistically significant risk factors effecting frequency and impact, the hierarchical cluster analysis method can be used, especially centroid clustering (Anderberg, 1973). This procedure attempts to identify relatively homogeneous groups of the strength of dependency of critical severe events on risk factors based on asymmetric Somers's $d$ statistics. 


\subsection{Measure of the ordinal variance}

Statistical analysis of the data obtained in the questionnaire survey starts with the descriptive and graphical analysis. For assessment of the level of an ordinal variable, the median is usually used and for measures of variability, the standardized measure of ordinal variance compared with the observed maximum of the ordinal variable is computed according to the formula:

$$
\text { dor } \operatorname{var}=\frac{4}{K-1} \sum_{i=1}^{K} C F_{i}\left(1-C F_{i}\right),
$$

where $K$ represents the number of categories, $C F_{i}$ denotes cumulative relative frequency of the i-th category. Dor var statistic measure can get the value from the interval $\langle 0 ; 1\rangle$, where the zero value indicates that the only one category is represented in an ordinal variable.

\subsection{Examining of dependencies of ordinal variables}

Numerous and varied measures of association can be used to describe the relationships between categorical variables with ordinal scales (Hanclova, et al., 2014). They tell us not only about the strength of the association but also about the direction. We will consider the ordinal measures of association based on the difference between the number of concordant pairs $(C)$ and the number of discordant pairs (D), calculated for all distinct pairs of observations. A pair of cases is concordant if the value of each variable is larger (or each is smaller) for one case than for the other case. A pair of cases is discordant if the value of one variable for a case is larger than the value for the other case but the direction is reversed for the second variable. The coefficient of association gamma, also called Goodman and Kruskal's gamma, is a symmetric measure which varies from -1 to +1 , based on the difference between concordant pairs and discordant pairs:

$$
\Gamma=\frac{C-D}{C+D} .
$$

Frontier values are gained in all cases, if $D=0$ (then $\Gamma=1$ ), resp. $D=1$ (then $\Gamma=-1)$. The intensity of the dependency between focused variables is decreased, it can be pointed, that gamma association of ordinal variables is overestimated. For this reason, an asymmetric extension of gamma - Somers' $d$ will be used. It differs only in the inclusion of the number of pairs not tied on the independent variable. A symmetric version of this statistic is also calculated as follows:

$$
d_{Y / X}=\frac{C-D}{C+D+T_{Y}}=\frac{2(C-D))}{n^{2}-\sum_{i} n_{i+}^{2}},
$$

where $T_{Y}$ is a number of pairs tied on $Y$, but with a different value of $X . n_{i+}$ defines absolute marginal frequencies of rows in the contingency table of 
variables $X$ and $Y$. The advantage of this association is the asymmetric measure of dependency $Y$ on $X$. Somers' $d$ is a measure of association between two ordinal variables that ranges from -1 to 1 . Values close to an absolute value of 1 indicate a strong relationship between the two variables, and values close to $O$ indicate little or no relationship between the variables.

Test the null hypothesis that there is no association between the variables using the chi-square statistic. If $H_{0}$ is rejected, then determine the strength of the association using Somers' $d$ statistic. If $H_{0}$ is rejected, then determine the strength of the association using the magnitude, and the direction of the relationship using the sign of the test statistic.

\section{CONCEPTION AND STRUCTURE OF THE QUESTIONNAIRE SURVEY}

The questionnaire survey has been chosen as a basic tool for the identification, analysis and evaluating the severe events and risk factors. In this section, the conception and structure of the questionnaire, the procedure for gathering data and the basic identifications of the respondents are described.

\subsection{Conception of the questionnaire survey}

The research conception has resulted from the theoretical findings about SCRM, methods for questionnaire survey design, experience from the similar surveys, data availability and brainstorming discussion of the research team. Persons from the manufacturing, manufacturing-distribution and distribution enterprises were the respondents. The emphasis was given to selecting those with positions such as logistic managers, purchasing managers, manufacture and distribution specialists, and company managers. The other criteria of selection were to include representatives of all various members of a supply chain, several industry fields, small-and-middle enterprises, big corporations, type of owners (local, foreign, both), and the rate of repetitiveness of production. Questions of all blocks were designed to be closed and were supplemented by open questions in order to allow problems to be expressed in more detail. The questionnaire was divided into 5 mutually linked sections, denoted as A, B, C, D and E. These five sections were supplemented by the identification section of respondents. Figure 2 summarizes the structure of the questionnaire survey.

In the section A (severe events in supply chains), it is dealt with the frequency of occurrence of the severe events (A1.x) and the analysis of the impact of these severe events on business performance (A2.x), where $\mathrm{x}$ denotes the sequential number of a particular severe event. With a help of literature, professional experience and brainstorming techniques of the research team, ten severe events were defined (i.e. $\mathrm{x}=1,2, \ldots, 10)$ : 'violating of negotiated terms against customers' (A1), 'need to fulfil supplies to customers in parts with increased costs' (A2), 'problems with a quality against customers' (A3), 'lack of inventories' (A4), 'surplus of inventories' (A5), 'depreciation of inventories' 
(A6), 'rejecting of contracts on account of unrealizable requirements of customers' (A7), 'lack of contracts' (A8), 'incapability to stand prices negotiated with customers' (A9), 'cancelling of semi-finished contracts by customers' (A10). There was used a scale of six grades for severe events A1.x: 1(never), 2 (very rarely), 3 (sometimes), 4 (often), 5 (very often) and 6 (all the time). For an appraisal of severe events according to the level of the impact A2.x, a six grade scale was also used, where: 1 (no impact), 2 (small losses), 3 (middle-sized losses), 4 (heavy losses), 5 (very huge losses) and 6 (threat of the company survival).

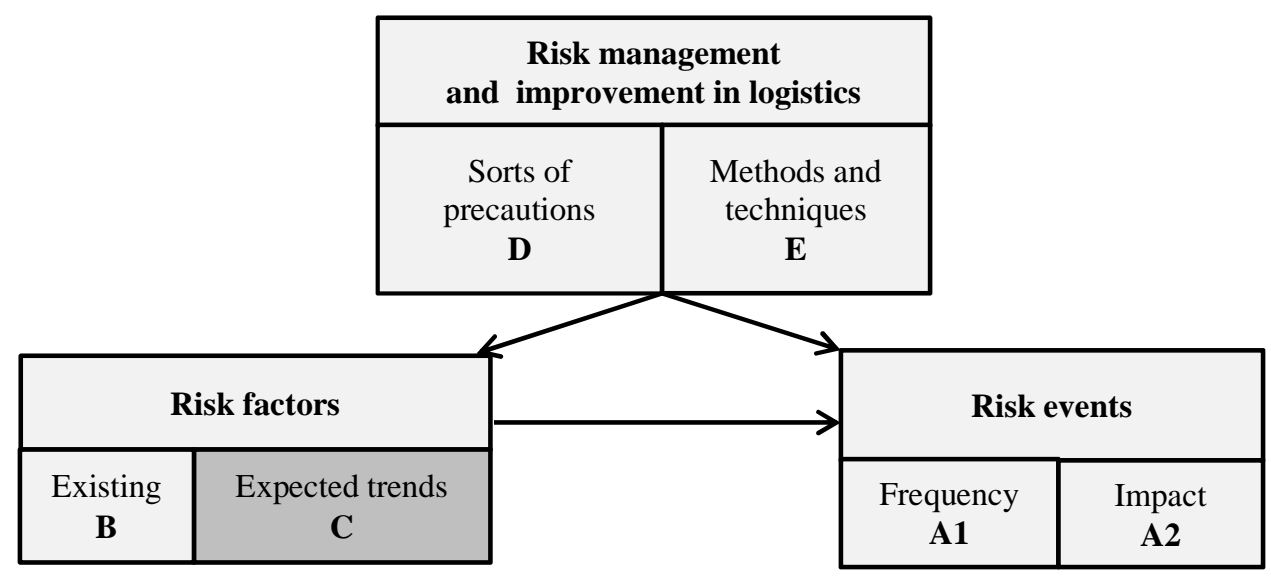

Figure 2 - Scheme of structure of the questionnaire survey

In the section B (risk factors in SC), the risk sources (causes) are analysed. Risk factor classification was set according to the combination of risk division into internal-external and hereafter uses structuring of risks according to effects on processes of a focus company in SC. The resulting structure is illustrated in Figure 3. Risk factors are then divided in 5 groups: B1 (risks on the demand side), B2 (risks on the supply side), B3 (risks of internal processes), B4 (risks of managing company), and B5 (external environment risks). A description of the risk factor labels is included in Annex A.

The first set of risk factors - B1 includes internal and external risks resulting from the demand side (dependency on a small number of big customers, high demands of customers on delivery terms, unpredictable fluctuations of demand, problems of customers with payments, etc.) The second set of risk factors B2 contains risks both on the buyer-side and on the side of distribution (dependency on a small number of dominant suppliers, bankruptcy of suppliers, long delivery terms in respect of demand fluctuation, quality and reliability of deliveries, supplier localization, structure of the SC, dependency on a specific means of transport, damage on delivery). The third set of risk factors B3 works with risks floating from internal processes of SC (complexity of the structure of internal SC, low quality against negotiated demands, unreliability of manufacturing facilities, storage systems, information systems, failures of a human factor, 
dependency of processes on the know-how of several key employees, financing of operations). The fourth set of risk factors $B 4$ includes both internal and intercompany risks of managing (insufficient technical preparation, procedures for correct calculation, unclear responsibility setting inside or outside a company, nonexistence of procedures documentation, wrong communication inside or outside a company, insufficient inventory level management, insufficient methods for demand forecasting, supplier selection, methodology of planning and manufacturing control, poor utilization of indicator of measurement and assessment of services, controlling of costs). The last set of risk factors B5 focuses on other risks from the external environment (rises in prices and duties, loans availability, legislative limitations, public infrastructure disruptions, natural disasters, terrorist attacks and wars, threat of strikes of employees).

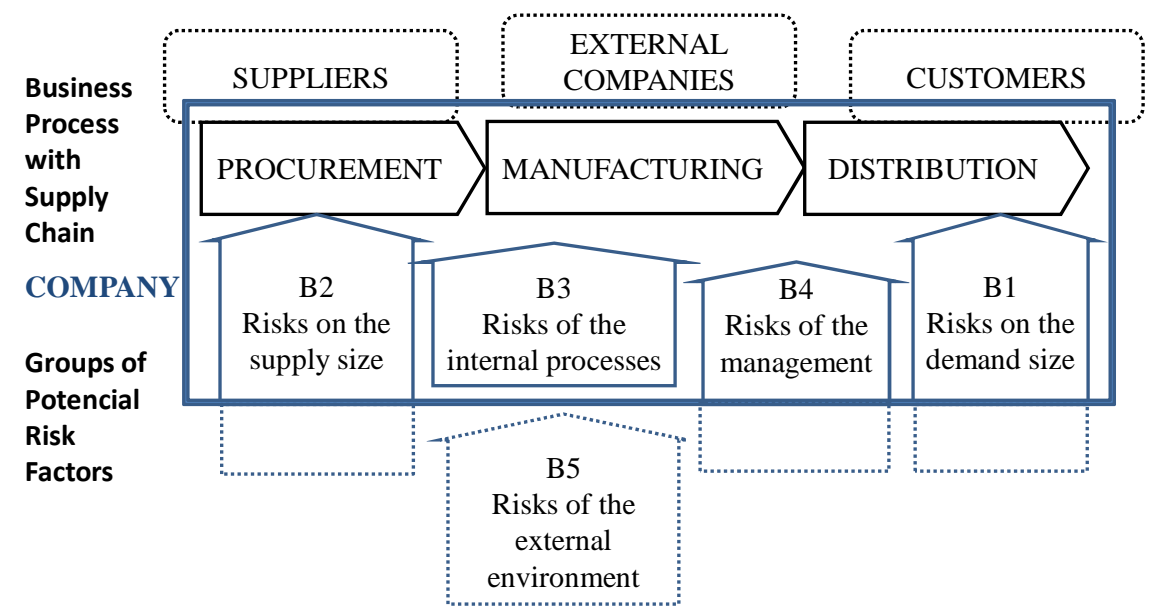

Figure 3 - Classification of risk factors in a focus company of SC

Overall, there were 5 key risk factors sets to be examined with 46 specified risk sources. The importance of the mentioned risk factors was assessed by respondents with the use of six grade scale: 1 (no significance), 2 (imponderable and irregular), 3 (imponderable and regular), 4 (partial sometimes), 5 (predominant), and 6 (everlasting).

Section C (Expected trends in SC risks) contains open questions relevant to expected changes in the area of SC risks in the following two years. In the section D (Managing the risks), approaches to risk management in respondents' companies are investigated. In the Section E (Improvements in SC), procedures and methods for improving the performance of SC were examined.

To summarize the contents of questionnaire, for 10 severe events occurring in SC the dependence on 46 risk factors classified in 5 risk factors groups will be examined. Additionally, attention is given to 20 types of possible precautions and actions for risk management and 11 methods and techniques of managing for improvements of performance in SC. 


\subsection{Analysis of the identification data of the respondents}

The questionnaire survey was realized in three phases during a time period of June 2010 up to October 2010 in manufacturing and manufacturing distribution companies, especially of the Moravian-Silesian and Olomouc regions. In the first phase respondents were selected and addressed on the basis of past cooperation with other researchers, in the second phase respondents were selected from the database Albertina and in the last phase respondents were addressed only by emails. The overall rate of return of the questionnaire survey was $30.3 \%$, i.e. 82 questionnaires were useful for analysis. Data were collected with the use of MS Excel and then exported to the statistical software SPSS.

A brief analysis of the structure of respondents will be carried out. All valid questionnaires were classified with regard to the business field, number of employees, type of production, position in SC, work position of respondents, and according to ownership.

From the view of business branch, $35 \%$ of respondents were from the machinetools industry, $14 \%$ of respondents were from the automotive industry, $12 \%$ of respondents were from the pharmaceutical and chemical industry, and the same amount from electrotechnics. Rubber and plastic industry were represented with $10 \%$, metals production formed $9 \%$, grocery industry took $7 \%$, and paper and cellulose industry only had $1 \%$ of respondents. Classification of respondents according to number of employees was relatively uniform with $32 \%$ with less than 50 employees, $31 \%$ with number of employees from 50 to 250 , and $37 \%$ of respondents belonged to companies with more than 250 employees.

Analysis of the SC position showed that the final product manufacturers took the largest portion of $44 \%$, suppliers at all levels of SC formed altogether $47 \%$, and rest of respondents were distributors. From the work position of respondents, there were $27 \%$ from logistic managers, and the same percentage from members of top management, $15 \%$ from specialists in purchase or inventory, $11 \%$ from manufacture planning and operating, 15\% distributors, and 5\% from economic and finance sectors of firms. The last identifications analyzed the portion between mainly Czech or foreign owners with the result that $64 \%$ were from companies with mainly Czech owners and $36 \%$ of respondents belonged to companies with primarily foreign owners.

An analysis of identification data showed a relatively balanced structure of respondents with regard to various criteria.

\section{ANALYSIS OF SEVERE EVENTS AND CRITICAL EVENTS DETERMINATION}

After the exploring identification data, an analysis of severe events followed. All of these events were examined according to the frequency of occurrence and the 
impact on business performance. The severe events analysis proceeded in following steps:

- descriptive and comparative analysis of measures of location and variability of events frequency,

- analysis and comparison of measures of location and variability of events impact,

- designing a map of frequency-impact of severe events and their classification.

\subsection{Analysis of frequency}

Frequency of occurrence was taken from six grade scale of questions A1.x, where $\mathrm{x}=1, \ldots, 10$. With having ordinal variables, the median was taken as a measure of location and standardized measure of ordinal variance (dor var) as a measure of variability. A problem arose with expressing positive and negative deviation from the median. The deviation proved itself to be highly nonsymmetric. Negative deviation is acceptable because risk is smaller, but positive deviation is unadvisable for higher risk. Regarding this fact, severe events were primarily classified by the level of median and then according to the direction and level of deviation from median in boxplots.

The severe events' frequencies are sorted into 3 groups, as it is shown in the Table 1. The first group includes severe events with median at the level 3, i.e. central value is evaluated as "sometimes". Variability is 1 point minus, i. e. negative deviation by 1 grade down (decreasing of severe event frequency). These events can be assessed as critical from the point of view of frequency of their occurrence. Last two groups are formed by events with median at the grade 2 , i. e. "very rarely", and they differ only in the direction of variance.

Table 1 - Classification of severe events according to frequency

\begin{tabular}{c|c|l}
\hline Median & Deviation & Severe events \\
\hline $\mathbf{3}$ & - & $\begin{array}{l}\text { non-fulfillment of negotiated contract terms against customers (A1.1); } \\
\text { need to fulfill supplies to customers in parts with increased costs } \\
\text { (A1.2); lack of inventories (A1.4); lack of contracts (A1.8) }\end{array}$ \\
\hline $\mathbf{2}$ & + & $\begin{array}{l}\text { surplus of inventories (A1.5); rejecting of contracts on account of } \\
\text { unrealizable requirements of customers (A1.7); problems with the } \\
\text { quality against customers (A1.3) }\end{array}$ \\
\hline $\mathbf{2}$ & - & $\begin{array}{l}\text { incapability to stand prices negotiated with customer (A1.9); } \\
\text { depreciation of inventories (A1.6); cancelling of semi-finished } \\
\text { contracts by customers (A1.10) }\end{array}$
\end{tabular}

The classification of adverse events within these 3 groups can be further divided taking into account the ordinal measure of variance (dor var) of each event. The computed results of these statistics are summarized in Table 2. 
Table 2 - The ordinal measure of variance of severe events according to frequency

\begin{tabular}{c|c|c|c|c|c|c|c|c|c|c} 
Event & A1.1 & A1.2 & A1.3 & A1.4 & A1.5 & A1.6 & A1.7 & A1.8 & A1.9 & A1.10 \\
\hline Dor var & 0.386 & 0.389 & 0.240 & $\mathbf{0 . 4 5 1}$ & 0.402 & 0.295 & 0.88 & 0.431 & 0.325 & 0.290 \\
\hline Median & 3 & 3 & 2 & $\mathbf{3}$ & 2 & 2 & 2 & 3 & 2 & 2
\end{tabular}

\subsection{Analysis of impact}

Analogously to section 5.1, it is possible to estimate the impact of severe events on companies by questions $\mathrm{A} 2 \mathrm{x}$, where $\mathrm{x}=1, \ldots, 10$ and the impact classification is shown in the Table 3.

Table 3 - Classification of severe events according to impact

\begin{tabular}{c|c|l} 
Median & Deviation & Severe events \\
\hline $\mathbf{3}$ & - & lack of contracts (A2.8) \\
\hline $\mathbf{2}$ & + & problems with the quality against customers (A2.3) \\
\hline $\mathbf{2}$ & -+ & cancelling of semi-finished contracts by customers (A2.10) \\
\hline $\mathbf{2}$ & & need to fulfill supplies to customers in parts with increased costs (A2.2) \\
\hline $\mathbf{2}$ & - & $\begin{array}{l}\text { rejecting of contracts on account of unrealizable requirements of } \\
\text { customers (A1.7); lack of inventories (A2.4); incapability to stand prices } \\
\text { negotiated with customer (A2.9); surplus of inventories (A2.5); need to } \\
\text { fulfill supplies to customers in parts with increased costs (A2.1); } \\
\text { depreciation of inventories (A2.6) }\end{array}$
\end{tabular}

The computed results of the ordinal measure of variance (dor var) of each event are presented in Table 4. The most critical event was determined to be A2.8, i. e. lack of contracts, where the median grade was at the value 3 "middle-sized losses" and the deviation was 1 grade down.

Table 4 - The ordinal measure of variance of severe events according to impact

\begin{tabular}{l|c|c|c|c|c|c|c|c|c|c} 
Event & A2.1 & A2.2 & A2.3 & A2.4 & A2.5 & A2.6 & A2.7 & A2.8 & A2.9 & A2.10 \\
\hline Dor var & 0.343 & 0.270 & 0.321 & 0.373 & 0.343 & 0.309 & 0.424 & $\mathbf{0 . 4 7 8}$ & 0.346 & 0.368 \\
\hline Median & 2 & 2 & 2 & 2 & 2 & 2 & 2 & $\mathbf{3}$ & 2 & 2
\end{tabular}

\section{Classification of severe events}

For severe events classification, it is necessary to take into account not only the frequency of their occurrence but also the intensity of the impact of severe events in SC. The map of severe events location was developed from the integration of frequencies with impact into a two dimensional matrix ordering. This allows both factors to be considered. 
Table 5 demonstrates the map of severe events location in a XY space (frequency - impact). The most critical severe events are A8 (lack of contracts) with the same evaluation for frequency and impact (3-; 3-), and event A3 (problems with a quality against customers) with evaluation $(2+; 2+)$, and possibly the event A2 (need to fulfil supplies to customers in parts with increased costs) with evaluation (3-; 2). The other group can be formed by events with high impact but less frequent where falls the event A10 (cancelling of semi-finished contracts by customers). The third group consists of events with high frequency but a lower level of impact $(\mathrm{A} 1, \mathrm{~A} 4)$. The last group is formed by those severe events with both a low frequency of their occurrence and low level of impact (A6,A9,A5,A7).

Table 5 - Map of severe events location with regard to frequency and impact

\begin{tabular}{|c|c|c|c|c|}
\hline Impact (Y) & \multicolumn{5}{|l|}{} \\
\hline $\mathbf{3}-$ & & & & A8 \\
\hline $2+$ & & & A3 & \\
\hline $2-+$ & A10 & & & \\
\hline 2 & & & & A2 \\
\hline $2-$ & A6 & & A9 A5 & A1 A4 \\
\hline Frequency $(X)$ & $\mathbf{2}-$ & $\mathbf{2}$ & $\mathbf{2}+$ & $\mathbf{3}$ - \\
\hline
\end{tabular}

At the end of this analysis, and with conformity with the first partial objective, the lack of contracts (A8) can be determined as the most critical severe event both in term of frequency of occurrence and level of impact. Since the six grade scale was used, evaluation of frequency and impact of A8 on the grade 3 can be characterized as weak. Exposure of the lack of contracts as the most critical is not surprising because of the financial crisis in years 2008-9.

\section{ANALYSIS OF RISK FACTORS}

We used 46 risk factors, classified in 5 groups. An assessment of those risk factors was made by means of six grade scale for closed questions. An analysis of grouped and single risk factors was realized similarly as in severe events occurrence analysis. The results of the risk factor analysis are in a Table 6.

From the group of risks on a demand side, factors with medium importance are: 'dependency on a small number of big customers' (B1.1), 'high demands of customers on delivery terms' (B1.2) and B1.3 and B1.6. Other risk factors of this group occur with a low level of importance with insignificant presence. The second group evaluates risks both on the supply side, and purchase and distribution risks. The medium important risks is especially: 'dependency on a small number of dominant suppliers' (B2.1). The main portion of risk factors 
connected with internal processes is with a low significance (negligible and irregular occurrence).

In the risk factor group of risk management, the factor of 'insufficient demand forecasting' (B4.10) was determined as medium important with occasional occurrence. Other risk factors of this group pointed to the low importance level with negligible and irregular occurrence. The last group of risk factors followed the influence of external environment. Respondents ranked the 'rises in prices and duties' (B5.1), i. e. prices of inputs, taxes, rates and duties in transport, rentals of storage, and interests, to the important risk factors. Other factors occurred insignificantly.

Table 6-Evaluation of risks factors (label description of risk factors is given in Annex A)

\begin{tabular}{|c|c|c|c|c|c|c|c|}
\hline \multicolumn{3}{|c|}{ Characteristics } & \multicolumn{5}{|c|}{ Risk factors } \\
\hline $\begin{array}{l}\text { Relative } \\
\text { evaluation } \\
\text { of risk } \\
\text { importance }\end{array}$ & median & deviation & $\begin{array}{c}\text { B1 } \\
\text { demand }\end{array}$ & $\begin{array}{c}\text { B2 } \\
\text { supply }\end{array}$ & $\begin{array}{c}\text { B3 } \\
\text { internal } \\
\text { processes }\end{array}$ & $\begin{array}{c}\text { B4 } \\
\text { risks of } \\
\text { management }\end{array}$ & $\begin{array}{c}\text { B5 } \\
\text { external } \\
\text { environment }\end{array}$ \\
\hline \multirow[b]{2}{*}{ high } & 6 & & & & & & \\
\hline & 5 & & & & & & \\
\hline \multirow{5}{*}{ medium } & \multirow{3}{*}{4} & -+ & B1.1 & B2.1 & & & B5.1 \\
\hline & & --+ & B1.2 & & & & \\
\hline & & -- & $\begin{array}{l}\text { B1.3, } \\
\text { B1.6 }\end{array}$ & $\begin{array}{l}\text { B2.3, } \\
\text { B2.5 }\end{array}$ & & & \\
\hline & \multirow[b]{2}{*}{3} & -++ & & & & & \\
\hline & & -+ & & B2.4 & $\begin{array}{l}\text { B3.4, } \\
\text { B3.5 }\end{array}$ & B4.10 & \\
\hline \multirow{7}{*}{ low } & \multirow{5}{*}{2} & ++ & B1.5 & & $\begin{array}{l}\text { B3.1, } \\
\text { B3.3 }\end{array}$ & B4.1, B4.6 & B5.3 \\
\hline & & + & & B2.10 & & $\begin{array}{l}\text { B } 4.2 \text { B } 4.7, \\
\text { B } 4.8, \text { B } 4.9\end{array}$ & B5.4 \\
\hline & & -++ & B1.4 & B2.6 & & $\begin{array}{l}\text { B4.13, } \\
\text { B4.14, B4.15 }\end{array}$ & \\
\hline & & -+ & & $\begin{array}{l}\text { B2.7, } \\
\text { B2.8, } \\
\text { B2.9 }\end{array}$ & $\begin{array}{l}\text { B3.2, } \\
\text { B3.6 }\end{array}$ & $\begin{array}{l}\text { B } 4.3, \text { B } 4.4, \\
\text { B4.11, B4.12 }\end{array}$ & B5.2, B5.9 \\
\hline & & - & & B2.2 & & & B5.5 \\
\hline & \multirow[t]{2}{*}{1} & + & & & & B4.5 & \\
\hline & & & & & & & $\begin{array}{l}\text { B5.6, B5.7, } \\
\text { B5.8 }\end{array}$ \\
\hline \multicolumn{3}{|c|}{ ff risk factors } & 6 & 10 & 6 & 15 & 9 \\
\hline
\end{tabular}

In the risk factor group of risk management, the factor of 'insufficient demand forecasting' (B4.10) was determined as medium important with occasional occurrence. Other risk factors of this group pointed to the low importance level with negligible and irregular occurrence. The last group of risk factors followed the influence of external environment. Respondents ranked the 'rises in prices and duties' (B5.1), i. e. prices of inputs, taxes, rates and duties in transport, 
rentals of storage, and interests, to the important risk factors. Other factors occurred insignificantly.

Demand side (4 risks) and supply side (3 risks) groups of risk factors and one external environment risk factor turn to be the most important with median level at 4 th grade. Analysis of single risks pointed out the most important risk sources, above all: dependency on a small number of big customers, high demands of customers on delivery terms, dependency on a small number of dominant suppliers, and rises in prices and duties.

\section{DEPENDENCE CRITICAL EVENTS ON RISK FACTORS}

In this section, the dependencies of critical severe event 'lack of contracts' on risk factors is examined using Somers'd measure of association. The dependencies were tested on both frequency and level of impact on companies in SC. The relationship classification will be performed by hierarchical cluster analysis.Testing the statistical significance of dependency of frequency and the impact of lack of contracts on individual risk factors

In the first step of this analysis, the asymmetric measure of dependence of the frequency or the impact of 'lack of contracts' on every risk factor will be examined. Statistically significant dependencies (values of the asymmetric Somer's $d$ statistics) are summarized in Table 7.

Table 7 - Dependency of 'lack of contracts' frequency A1.8 and impact A2.8 on Bx.y

\begin{tabular}{|c|c|c|c|c|c|}
\hline risk/event & A1.8 & A2.8 & risk/event & A1.8 & A2.8 \\
\hline B1.1 & 0.225 & 0.267 & $\mathbf{B 4 . 4}$ & 0.361 & 0.221 \\
\hline B1.2 & 0.221 & 0.232 & $\mathbf{B 4 . 6}$ & 0.200 & 0.207 \\
\hline B1.3 & & 0.229 & $\mathbf{B 4 . 7}$ & & 0.278 \\
\hline B1.6 & 0.265 & & $\mathbf{B 4 . 8}$ & & 0.273 \\
\hline B3.1 & & 0.344 & $\mathbf{B 4 . 9}$ & 0.188 & 0.209 \\
\hline B3.2 & 0.331 & 0.339 & $\mathbf{B 4 . 1 0}$ & & 0.135 \\
\hline B3.3 & 0.192 & 0.130 & $\mathbf{B 4 . 1 1}$ & & 0.242 \\
\hline B3.4 & & 0.260 & $\mathbf{B 4 . 1 2}$ & 0.308 & 0.268 \\
\hline B3.5 & 0.315 & 0.290 & $\mathbf{B 4 . 1 3}$ & 0.242 & 0.178 \\
\hline B3.6 & 0.274 & $\mathbf{0 . 3 5 9}$ & $\mathbf{B 4 . 1 4}$ & 0.267 & 0.199 \\
\hline B4.1 & 0.226 & 0.282 & $\mathbf{B 4 . 1 5}$ & 0.180 & 0.206 \\
\hline B4.2 & $\mathbf{0 . 4 0 5}$ & 0.281 & $\mathbf{B 5 . 2}$ & 0.311 & 0.328 \\
\hline B4.3 & 0.294 & 0.207 & $\mathbf{B 5 . 9}$ & 0.214 & 0.281 \\
\hline
\end{tabular}

Legend: label description of risk factors is given in Annex A.

For example, dependency of frequency of critical event 'lack of contracts' (A1.8) on the risk factor 'insufficient procedures for price calculation and economical effectiveness assessment" (B4.2) is 0.405. A strength of the positive association 
is at the low level and the null hypothesis (there is no association between the variables) is rejected using the chi-square statistic at $5 \%$ of significance level. Statistical significance of association was also confronted with economic theoretical background. The results in Table 7 show the important risk factors, determined according to influence the frequency and impact of severe event 'lack of contracts' (A8). We identified also 18 risk factors influencing both sides. This finding brings the conclusion that if we want to reduce frequency, we mainly aim on risks with effect on the frequency and if we want to reduce impact of risk event, we aim on risks with effect on the impact.

The lack of contracts appears to be high both in frequency and in impact, so the risks to be handled at first are:

- 'low quality against negotiated requirements' (B3.2) - Somers' $d>0.3$ on both sides,

- 'unclear responsibility between external partners' (B4.4), 'dependency of processes on the know-how of several key employees' (B3.5) and 'unsatisfactory level of the methodology for manufacture planning and processing' (B4.12) - Somers' $d>0.3$ according to the frequency of 'lack of contracts' $A 8$, and

- 'financing of operations' (B3.6), 'complexity of internal logistic chains' (B3.1) and 'unreliability of manufacturing facilities, storage systems, information systems' (B3.3) - Somers' $d>0.3$ according to impact of severe event A8.

This procedure, described above, can help companies to identify important risk factors influencing critical risk events and it also creates the basic platform for modeling and simulation techniques utilization with a linkage to optimization of cost/benefit side or production effectiveness.

\section{Classification of individual risk factors according to statistically significant strength of effect on lack of contracts}

For graphical plotting of the strength of risk factors influences on frequency and the impact of critical severe events, a scatter plot is used in Figure 4. The strength was measured by Somers's $d$ statistic in absolute value and with a significance level not higher than 5\%. The graphical presentation shows that the risk factors influencing the critical event 'the lack of contracts' (A8) could be classified into 4 clusters using hierarchical clustering.

Cluster 4 includes those risk factors which are to be analyzed and dealt with because they have the biggest effect. There are 5 factors from the 46 selected in this cluster, in list: 'financing of operations' (B3.6), 'low quality against negotiated requirements' (B3.2), 'difficulties with loans gaining for covering of logistic costs' (B5.2), 'dependency of processes on the know-how of several key 
employees' (B3.5), and 'unsatisfactory level of the methodology for manufacture planning and processing' (B4.12), where with bold font denoted factors was identified as medium important with regular occurrence. Cluster 3 contains the risk factor 'insufficient procedures for price calculation and economical effectiveness assessment' (B4.2) and 'unclear responsibility between external partners' (B4.4), which causes effects especially on the frequency of the 'lack of contracts' but its influence on the impact is insignificant. Cluster 2 is characterized by the significant dependency of the event's impact on risk factors but with a low influence of risk factors to the event frequency: "unreliability of manufacturing facilities, storage systems, information systems' (B3.3), 'treat of mass leavings of employees to firms with better conditions' (B5.9), 'insufficient or low-quality technical documentations of manufacture' (B4.1) and 'dependency on a small number of big customers' (B1.1). The last Cluster 1 is the least important because it is formed by 20 statistically insignificant risk factors. This clustering approach is applicable for every severe event.

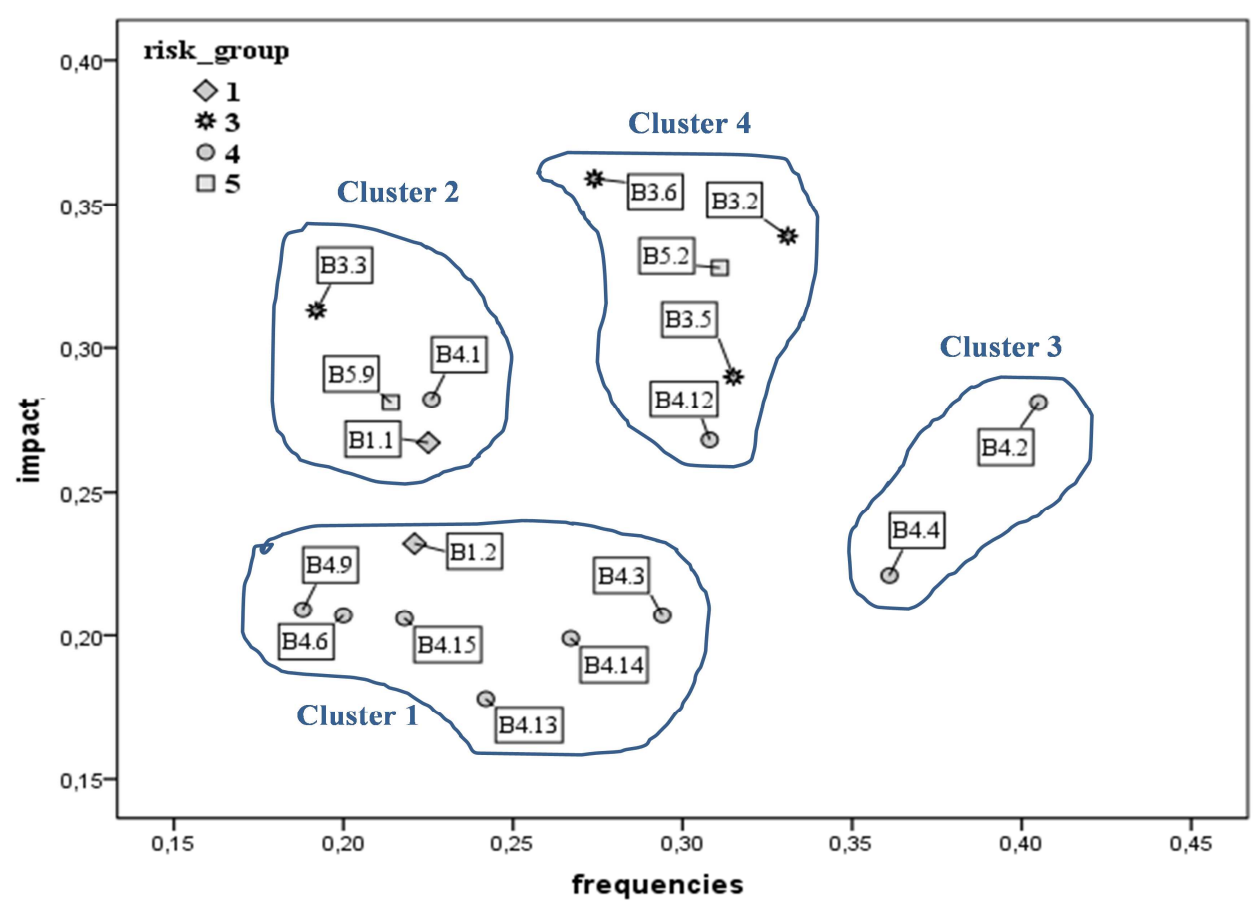

Figure 4 - The strength of effects of risk factors on frequency and impact of event A8

\section{CONCLUSION}

The focus on this paper is given to an analysis and evaluation of severe events in the supply chains of primarily manufacturing firms. Companies in a SC are influenced by various risk factors which affect the frequency of occurrence and 
impact of severe events. This paper proposed how to classify severe events according to their frequency of occurrence in companies and their impact on companies, then to classify the risk sources and determine the major risks.

In the paper, we continue the analyses in searching for relationships and for dependencies of severe events on single risk factors using estimated Somers'd statistics separately for frequencies and impact of the severe events. We performed a graphical plotting of strengths of influences of risk factors into a two dimensional scatter plot and with a supplementary cluster analysis we can determine the risk factors groups influencing only frequency, or only impact, or both dimensions.

For the 10 examined severe events in the SC, the most critical was found to be event 'lack of contracts' (A8) - taking account of both frequency and the level of impact on companies. This critical severe event obtained the result (3-; 3-) in a six grade scale which means casual and irregular occurrence and middle-sized impact on business health and performance. In relation to the economic crisis, lack of contracts can be considered as likely to be a critical event. Other relatively critical events were 'need to fulfill supplies to customers in parts with increased costs" (A2) with the result occurrence close to the level "sometimes" and impact of "low loses", and "problems with the quality against customers" (A3) with the occurrence at level "very rarely and the impact at level "low loses".

The classification and evaluation were based on location measurement by median and variability. Analysis of risk factors was carried out for 46 defined risk sources, sorted into 5 groups (demand, supply, internal processes, risk of management, and external risks). In terms of assessing risk groups, it was confirmed that no source of risk had been ignored in the worst - the most important group (i.e. high, grade 5-6). In the results, it is shown that the most significant sources of risk factors are groups of demand and supply side and one very important risk factor was identified in an external factor group. The most important risks have the highest level of median 4 th grade. The reason can be found in respondents' discretion about problems in a company, where they work, as it was mentioned above. The most significant risk factors are 'dependency on a small number of big customers', 'high requirements of customers on the terms of delivery', 'dependency on a small number of dominant or special suppliers', and 'rises in prices and duties'. It is then obvious that where are the stronger problems with the bargaining power of the focal company, and where is then more problematic to diversify risk factors both on the supply and the demand side, more disruptions and dependencies take negative effects.

In the third empirical part, we examined the links of risk sources and their influence on the most critical event 'lack of contracts' (A8) using an asymmetric measure for ordinal variables association. A hierarchical cluster analysis was used to classify relationships according to occurrence and impact. The worst cluster 4 , encompassing $11 \%$ of examined risk factors, proved the evidence of the influence of not only the severe event occurrence but also its impact on 
companies. There are 5 risk factors in this cluster: risks of the internal processes ('low quality against negotiated requirements', 'dependency of processes on the know-how of several key employees', 'financing of operations'), risk of management ('unsatisfactory level of the methodology for manufacture planning and processing'), and external risk factor ('difficulties with loans gaining for covering of logistic costs'). In other significant clusters (2 and 3), risk sources are contained from the point of view of either impact or occurrence. The last cluster 1 is formed by unimportant or insignificant risk factors. This list of risk sources is possible to be plotted into scatter plot and analogically to the SWOT analysis, design a plan to deal with the risks in SCs and inside particular companies. This process cannot be understood as closed because turbulent internal and external environment influence both single companies and entire SC during any time period.

In our survey, it was confirmed that SC risk intensification can be expected, therefore the necessary condition for flexible behavior is to deal with risk management systematically not only at a company level but at the more complex supply chain or network level too. For a group of influenceable risks, register of risks is proper to create, evaluate the relationships forwards severe events, and develop precaution principles gradually and continuously.

The possibilities for further research can be seen in an examination of relationships among severe events, risk factors, etc., in order to analyze chain effects among severe events or risks, for example, if the surplus of inventories leads to their depreciation, etc. The analysis is necessary to pursue repeatedly in order to obtain the dynamics in the risk environment. With regard to respecification of the questionnaire survey in scale of answers and sample sizes, various model designs, e.g. the ordinal regression model, can be still considered.

If problems of severe events occurrence and risk factors effects are explored the SCRM should also aim the focus on the core processes connected with the critical severe events and risk factors, analyze them and run changes in order to provide improvements.

\section{ACKNOWLEDGMENTS}

This paper was created under SGS project (SP/201085) of Faculty of Economics, VŠB-Technical University of Ostrava and Operational Programme Education for Competitiveness - Project CZ.1.07/2.3.00/20.0296. 


\section{ANNEX A - THE LIST OF RISK FACTORS}

\section{B1 - Risks on the demand size}

B1.1 - dependency on a small number of big customers,

B1.2 - high requirements of customers on the terms of delivery,

B1.3 - high and irregular fluctuations in demand,

B1.4 - demand fluctuations from the reason of sales supporting actions,

B1.5 - campaigns in demand,

B1.6 - problems of customers with payments.

B2 - Risks on the supply size

B2.1 - dependency on a small number of dominant or special suppliers,

B2.2 - risk of suppliers' bankruptcy,

B2.3 - long terms of delivery of suppliers with regard to demand changeability,

B2.4 - problems with the service level of deliveries (quality, delivery terms reliability, quantity, cover documents),

B2.5 - insufficient of items on market leading to high price,

B2.6 - suppliers do not provide important information about treating problems on time,

B2.7 - suppliers are located in a distant and hardly accessible territory,

B2.8 - complexity of SC by reason of many interfaces (purchase, distribution, transshipments, controls between various subjects),

B2.9 - dependency of the flow process on means of transport,

B2.10 - damages of deliveries by another subject (distributor).

B3 - Risks of the internal processes

B3.1 - complexity of internal logistic chains (many processes, flows, components),

B3.2 - low quality against negotiated requirements,

B3.3 - unreliability of manufacturing facilities, storage systems, information systems,

B3.4 - error rate of employees in the manufacture, warehouses, and by maintenance,

B3.5 - dependency of processes on the know-how of several key employees,

B3.6 - financing of operations.

B4 - Risks of the management

B4.1 - insufficient or low-quality technical documentations of manufacture,

B4.2 - insufficient procedures for price calculation and economical effectiveness assessment,

B4.3 - unclear responsibility of logistic chains inside a company,

B4.4 - unclear responsibility between external partners,

B4.5 - non-existence of well-documented procedures for orders handling, purchasing, manufacture planning and realizing,

B4.6 - wrong communication between departments of purchase - manufacture - sales,

B4.7 - wrong communication with suppliers,

B4.8 - wrong communication with customers,

B4.9 - insufficient level of inventory management system (evidence and replenishment),

B4.10 - inadequate system of demand prediction,

B4.11 - small seriousness and objectivity in suppliers selecting and evaluating,

B4.12 - unsatisfactory level of the methodology for manufacture planning and processing (long time horizon of planning, slow reactions on changes, missing capacity calculations),

B4.13 - non-utilization of indicators for logistic services level inside a company,

B4.14 - non-utilization of indicators for logistic services level between companies,

B4.15 - Inadequate measurement and controlling of logistic costs.

\section{B5 - Risks of the external environment}

B5.1 - rises in prices and duties (input costs, taxes, rents, interests),

B5.2 - difficulties with loans gaining for covering of logistic costs,

B5.3 - legislative limitations in logistics (overtimes limits, lorry usage limits, requirement of certificates, limits in night operations, etc.)

B5.4 - public infrastructure disruptions (traffic jams, accidents, closures),

B5.5 - natural disasters (floods, earthquakes, windstorms, etc.),

B5.6 - terroristic attacks, war conflicts,

B5.7 - sabotages,

B5.8 - strikes,

B5.9 - treat of mass leavings of employees to firms with better conditions. 


\section{REFERENCES}

Anderberg, M. R., 1973. Cluster analysis for applications, New York: Academic Press.

Basl, J. and Doucek, P., 2013. ICT and innovations in context of the sustainable development. In: 21st Interdisciplinary Information Management Talks: Information Technology Human Values, Innovation and Economy IDIMT 2013. Prague, Czech Republic, Sept. 11-13 September 2013. Linz: Trauner.

Blome, C. and Schoenherr, T., 2011. Supply chain risk management in financial crises - A multiple case-study approach. International Journal of Production Economics, 134(2), pp.43-57.

Council of Supply Chain Management Professionals, 2013. Supply Chain Management Terms and Glossary. [online] Available at: http://cscmp.org/sites/default/files/user_uploads/resources/downloads/glossary2013.pdf [Accessed 10 September 2014].

Delina, R. and Drab, R., 2010. Socio-economic aspects of trust building for the electronic business platforms. E + M Ekonomie \& Management, 13(4), pp. 110122.

Dorcak, P. and Delina, R., 2011. Impact of E-marketing Services on Economic Performance. Ekonomický časopis, 59(1), pp. 44-58.

Hanclova, J. and et al., 2014. The Determinants of IT Adoption in SMEs in the Czech-Polish Border Areas. Information Technology for Development. [online] Available at: http://www.tandfonline.com/loi/titd20 [Accessed 10 September 2014].

Hunter, L.M. and et al., 2004. A classification of business-to-business buying decisions: risk importance and probability as a framework for e-business benefits. Industrial Marketing Management, 33(2), pp.145-154.

Li, S. and Lin, B., 2006. Accessing information sparing and information quality in supply chain management. Decision Support Systems, 42(3), pp.1641-1656.

Macurová, P. et al., 2011. Rizika v logistice - poznatky z průzkumu. Littera Scripta, 4(1), pp. 41-52.

Matook, S., Lasch, R. and Tamasche, R., 2009. Supplier development with benchmarking as part of a comprehensive supplier risk management framework. International Journal of Operations \& Production Management, 29(3-4), pp.241-267.

Norrman, D. and Jansson, U., 2004. Ericsson's proactive supply chain risk management approach after a serious sub-supplier accident. International Journal of Physical Distribution \& Logistics Management, 34(5), pp.434-456. 
Ritchie, B. and Brindley, C., 2007. Supply chain risk management and performance: a guiding framework for future development. International Journal of Operations \& Production Management, 27(3), pp.303-322.

Tang, C., 2006. Perspectives in supply chain risk management. International Journal of Production Economics, 103(2), pp.451-488.

Tang, O. and Musa S.N., 2011. Identifying risk issues and research advancements in supply chain risk management. International Journal of Production Economics, 133 (1), pp.25-34.

Trkman, P. and McCormack, K., 2009. A conceptual model for managing supply chain risk in turbulent environment. International Journal of Production Economics, 119(2), pp. 247-258.

Trkman, P., Indihar Štemberger, M., Jaklič, J. and Groznik, A., 2007. Process approach to supply chain integration. Supply Chain Management: An International Journal, 12(2), pp.116-128.

Veber, J. and et al., 2000. Management. Základy-prosperita-globalizace. Praha: Management Press.

Waters, D., 2007. Supply chain risk management: vulnerability and resilience in logistics. London: Kogan Page.

\section{ABOUT THE AUTHORS}

Prof. José M. Caridad y Ocerin (1949) Dr. in Sciences and in Economics, Actuary. Professor of Statistics and Econometrics at the University of Cordoba (Spain) and head of its department. Member of the Spanish Statistical Society, president of SETIAM, member of the scientific committee of ACIE and of the Academy of Sciences in Cordoba, and consultant to several companies. Author in the last ten years of several books, and over a hundred articles in specialized journals and in proceedings of international conferences. Head of the research group PAI SEJ 281. The actual research is focused on quantitative methods in Economics, optimisation in distribution problems and business forecasting. In the business environment he has worked in the head office of the bank of Bilbao in its Statistical and O.R. department. E-mail: ccjm@uco.es

Jana Hančlová is an associated professor at the VŠB-Technical University of Ostrava, Faculty of Economics, Department of Systems Engineering. She is a member of the Czech Economic Society and the Czech Society for Operational Research. She has been a member of the expert commissions of the Czech Science Foundation for several years. She is an co-author of 12 monographs, 17 papers in the specialized journals and 69 articles in the conference proceedings. Her research priorities have included the investigation of structure, dynamics and 
disparities in regional markets, macroeconometric modelling of the EU economies, and operational research. E-mail: jana.hanclova@ @sb.cz

Josef Černý is a postgraduate student for Ph.D. degree at the VŠB-Technical University of Ostrava, Faculty of Economics, Department of Mathematical Methods in Economics. His research covers the application of mathematical methods to various fields of business administration and the management of enterprises, such as financial analysis, human resource management, and business environment analysis. He is particularly interested in logistics and process modelling, and the utilization of simulations in studying the supply chain. He is an author of 5 conference proceedings papers, 1 journal article, coauthor of 1 journal article, and co-author of 1 book aimed at risk management in logistics. He currently works at IBM International Service Center as accounting analyst. His work covers both ordinary accounting tasks and particular process improvements in accounting and reporting area.E-mail: josef.cerny.st2@vsb.cz 